\title{
Do Operating Systems Affect Perceptions of Smartphone Advantages and Drawbacks?
}

\author{
Ruti Gafni \\ The Academic College of Tel \\ Aviv Yaffo and the Department of \\ Management and Economics \\ The Open University of Israel, \\ Israel \\ rutigafn@mta.ac.il
}

\author{
Nitza Geri \\ The Department of \\ Management and \\ Economics \\ The Open University of \\ Israel, Israel \\ nitzage@openu.ac.il
}

\begin{abstract}
One of the major decisions that prospective consumers of a smartphone have to make is choosing its operating system. Currently, the most prevailing operating systems are Apple's iOS and Google's Android. This empirical study investigates if users of iOS and Android differ in their perceptions of the advantages and disadvantages of smartphones. The paper examines smartphone possessors' perceptions of the characteristics of their mobile phone use, when compared to consuming the same services via a computer. The main findings indicate that there were no significant differences between the users of the two operating systems with regard to the general characteristics of the smartphone as a mobile device. However, small differences were found in the perceptions of comfortableness and complexity of the devices. Only minor gender differences were observed. Plausible theoretical explanations, and implications of the findings, are discussed. This paper contributes to the informing science transdiscipline by providing insights regarding the effects of operating systems on users' perceptions of their personal mobile information system.
\end{abstract}

Keywords: mobile internet, smartphone adoption, period of ownership, operating system differences, iOS versus Android, smartphone advantages and disadvantages, mobile services.

\section{Introduction}

Smartphones are becoming ubiquitous (Smith, 2011), and mobile internet services are extensively used for various sorts of applications (Gerpott, Thomas, \& Weichert, 2012), including ecollaboration (Jones, 2012), e-learning (Cheong, Bruno, \& Cheong, 2012; Wong, Boticki, Sun, \& Looi, 2011), games (Ho \& Tu, 2012), and much more. Although technology acceptance and diffusion of innovation are one of the most studied areas in information systems research (Jeyaraj,

Material published as part of this publication, either on-line or in print, is copyrighted by the Informing Science Institute. Permission to make digital or paper copy of part or all of these works for personal or classroom use is granted without fee provided that the copies are not made or distributed for profit or commercial advantage AND that copies 1) bear this notice in full and 2) give the full citation on the first page. It is permissible to abstract these works so long as credit is given. To copy in all other cases or to republish or to post on a server or to redistribute to lists requires specific permission and payment of a fee. Contact Publisher@InformingScience.org to request redistribution permission.
Rottman, \& Lacity, 2006; Rogers, 2003; Venkatesh, Morris, Davis, \& Davis, 2003), very little research has been conducted about smartphone applications' adoption (Verkasalo, López-Nicolás, Molina-Castillo, \& Bouwman, 2010).

One of the major decisions that prospective consumers of a smartphone have to make is choosing its operating system. The decision, which operating system to 
choose, is based on their own perceptions, as well as perceptions and recommendations of others, while their opportunities to extensively try the devices beforehand are limited. It is important to investigate the perceptions of smartphone holders, who have been using the devices for a while. In order to gain a deeper understanding of the effects of operating systems on users' perceptions of advantages and disadvantages of smartphones, existing users of smartphone devices were selected for this empirical study. Currently, the most prevailing operating systems are Apple's iOS and Google's Android. Therefore, this study compared these two operating systems.

There are more factors involved in the selection decision of a smartphone, such as the available content and applications (Laugesen \& Yuan, 2010), or ideological considerations, like using free and open source software (FOSS) and open standards (Subramanian \& White, 2012). However, these issues are beyond the scope of this paper, which focuses on the perceived advantages and drawbacks of smartphone operating systems by people who have already bought them, and have been using them for a while.

This study contributes to the informing science transdiscipline (Cohen, 1999, 2009; Gill \& Bhattacherjee, 2009; Gill \& Cohen, 2009) by providing insights regarding the effects of operating systems on users' perceptions of their personal mobile information system, i.e., advantages and drawbacks of their smartphone. This empirical study is important, because only a few studies examined the adoption of smartphones, and most of them (e.g., Cheong et al., 2012) focused on smartphone applications, unlike this study that considers the device.

\section{Theoretical Context and Hypothesis Development}

The global research question of this study is whether operating systems affect smartphone possessors' perceptions of advantages and drawbacks of their device usage, when compared with consuming the same services via a computer. This study investigates three specific research questions (RQ), which originate from the global one:

RQ1: Which sorts of perceptions of smartphone advantages and drawbacks are affected by its operating system? This question is elaborated in the subsection "general versus operating-systemrelated characteristics".

RQ2: Are there gender differences of smartphone possessors' perceptions of advantages and drawbacks of their device usage? This question is developed in the subsection "gender differences"

RQ3: Does the period of possession of the smartphone affect its possessors' perceptions of advantages and drawbacks of their device usage? This question is explained in the subsection "period of possession".

\section{General versus Operating-System-Related Characteristics}

When comparing the consumption of mobile internet services via a smartphone with consumption of the same services via a computer, there are two main sorts of characteristics that should be considered separately: general characteristics of smartphone use, and characteristics that are affected or determined by the operating system.

General characteristics of smartphone use emanate from its mobility, or external factors of mobile internet services consumption. The mobility entails advantages such as the ability to use the smartphone anytime, and anywhere, and its being accessible since people usually carry it with them. However, the last advantage is related to a general disadvantage, because it means that the device must be small, and a small device may be hard to use, or limited in its functions (Barnes \& Huff, 2003; Gafni, 2008, 2009). 
A related general advantage is the ability to share information in real time, e.g., using social network applications (Jones, 2012), such as Facebook and Twitter. Yet another advantage is enhancing the smartphone holder's image, as a person who is using a trendy technological gadget. However, there are two associated general disadvantages, security issues related to the device use (e.g., theft, exposure of personal information), and the price of using the smartphone, which may be considered as high.

These general characteristics are common for all the smartphones, regardless of their operating systems. Therefore, it is not expected that there will be differences between perceptions of smartphone holders who use different kinds of operating systems with regard to their general characteristics.

H1: There are no differences between users of alternative operating systems in their perceptions of general advantages and drawbacks of smartphone use for consumption of internet services.

The second sort of smartphone characteristics is those that are affected or determined by the operating system. As previously mentioned, the availability of content that is designed for a certain operating system and the openness of the system (Subramanian \& White, 2012) are beyond the scope of this paper. However, two main relevant characteristics are examined here. The first one is presented as an advantage: the comfortableness of the smartphone use, while the second one is presented as a disadvantage: the complexity of the smartphone use. It is expected that users of different operating systems may differ in their perceptions of their devices' comfortableness and complexity.

H2: There are differences between users of alternative operating systems in their perceptions of operating-system-related advantages and drawbacks of smartphone use for consumption of internet services.

\section{Gender Differences}

Similar to the discussion above of operating systems and their potential influence on user perceptions of advantages and drawbacks of smartphones, which distinguished between general and operating-system-related characteristics, we postulate that the same distinction is relevant for gender. There should be no reason to assume that there are gender differences with regard to the general characteristics. Specifically, if it concerns generation Y (Kumar \& Lim, 2008) users, who were born after 1981, and are more used to advanced technologies. This may be the case also with characteristics that are affected by the operating system, such as comfortableness and complexity. Nevertheless, females are sometimes perceived as having more difficulties with handling technological gadgets, or information systems. The hypotheses are phrased as if no differences are expected, and there is no indication of an expected direction of such a difference.

H3: There are no gender differences between smartphone users in their perceptions of general advantages and drawbacks of smartphone use for consumption of internet services.

H4: There are no gender differences between smartphone users in their perceptions of operatingsystem-related advantages and drawbacks of smartphone use for consumption of internet services.

\section{Period of Possession}

We continue the thread of distinction between general characteristics and operating-systemrelated characteristics, while discussing the effect of time on perceptions. It should be expected that there would be no correlation between the period of possession of the smartphone and users' perceptions of its general characteristics. 
H5: There is no correlation between the period of possession of a smartphone and users' perceptions of general advantages and drawbacks of smartphone use for consumption of internet services.

However, as time goes by, people may get used to the characteristics of the smartphone that are affected by the operating system (Jiang, 2009; Limayem, Hirt, \& Cheung, 2007; Polites \& Karahanna, 2012), such as comfortableness and complexity.

H6: There is a correlation between the period of possession of a smartphone and users' perceptions of operating-system-related advantages and drawbacks of smartphone use for consumption of internet services.

\section{Methodology}

At the time of data collection, May, 2012, while smartphone adoption was rapidly growing, it was relatively difficult to independently locate people who had a smartphone. Therefore, the snowball sample selection method (Corbitt, Thanasankit, \& Yi, 2003; Peffers \& Tuunanen, 2005) was used.

The data was collected by undergraduate students who participated in a compulsory research methods course, at a college located in central Israel. Each one of the 60 students was required to find 10 adults willing to answer a survey, which was identical for all the 600 participants. The students themselves were allowed to answer the survey only once, provided that they had a smartphone, either as one of the participants in their own 10 respondents group, or as respondents to one of their classmates' group.

In order to increase the homogeneity of the sample, it was required that the participants should be at least 20 years old. The students interviewed their family members, friends, neighbors, or other acquaintances. While these convenience samples might have affected the generalizability of the findings, they increased the homogeneity of the participants, who generally lived in the same region, mainly belonged to the same middle class socio-economic group, and were under similar cultural influences. The respondents' identity was kept anonymous, but the students had to provide some details about the participants that allowed ensuring that the same person did not answer more than one survey. Other mechanisms were used to verify the validity of the collected data.

The participants of the survey were asked to rank their perceptions of six advantages of using internet services via their smartphone compared to consuming the same services via a computer. The perceptions were measured on a scale of 1 to 4 (not an advantage; an advantage to a small extent; an advantage to a large extent; an advantage to a very large extent), where a higher score meant a higher perception of the smartphone's advantage. The advantages are listed in Table 1. Similarly, the participants were asked to rank four disadvantages. The perceptions were measured on a scale of 1 to 4 (a disadvantage to a very large extent; a disadvantage to a large extent; a disadvantage to a small extent; not a disadvantage), where a higher score meant a smaller perception of the smartphone's disadvantage. The disadvantages are listed in Table 1.

A five-point scale was not used intentionally, and the mid-point was eliminated so the participants would not choose it in order to please the interviewer, or avoid providing a socially unacceptable answer (Garland, 1991). This issue was important due to the snowball sample selection method that was used in this study, and the acquaintanceship of the participants with the students who collected the data. Indeed, a small percentage of the participants did not answer the somewhat delicate question regarding the image advantage of using a smartphone, and the average score of those who answered this question may be biased downwards, because perhaps people did not want to admit that they thought that using a smartphone improved their image. 
It took about 10-15 minutes to answer the survey, which included additional information that is not included in this analysis. The data of the 600 completed surveys was integrated by one of the authors. A few exceptional questionnaires were excluded. Furthermore, since most of the participants had smartphones with either Apple or Android operating systems, it was decided to exclude the participants who had other operating systems, such as Blackberry. Additionally, with the purpose of further increasing the homogeneity of the sample, and specifically decrease age effects (Gafni \& Geri, 2013; Kumar \& Lim, 2008; Morris \& Venkatesh 2000; Venkatesh, Thong, \& Xu, 2012), the sample was restricted to people aged 20-30. It was also decided to omit incomplete records. Consequently, there were 362 usable records.

\section{Results}

The data was analyzed with IBM ${ }^{\circledR}$ SPSS $₫$ Statistics, version 20 . There were 362 participants in the final sample, aged 20 to 30 (mean=26.07, $\mathrm{SD}=1.618), 223$ males $(61.6 \%)$, and 139 females $(38.4 \%)$. Independent samples t-tests (2-tailed) conducted for the entire sample, showed no gender differences in seven out of the ten examined characteristics of smartphones. However, males perceived the possession of a smartphone as adding to their image (mean $=2.05, \mathrm{SD}=1.001$ ) slightly higher than females did (mean $=1.76, \mathrm{SD}=1.047),(\mathrm{t}=2.605, \mathrm{p}=.010,360 \mathrm{df}$, equal variances assumed, Levene's test for equality of variances: $\mathrm{F}=1.387, \mathrm{p}=.240$, Cohen's $\mathrm{d}=.28$ ). Females perceived smartphones as less secure (mean $=2.58, \mathrm{SD}=1.006)$ than males did (mean $=2.91, \mathrm{SD}=$ $1.011),(\mathrm{t}=2.962, \mathrm{p}=.003,360 \mathrm{df}$, equal variances assumed, Levene's test for equality of variances: $\mathrm{F}=1.215, \mathrm{p}=.271$, Cohen's $\mathrm{d}=.33$ ). Females also perceived smartphones as more complex (mean=2.99, $\mathrm{SD}=.978)$ than males did (mean=3.21, $\mathrm{SD}=.926),(\mathrm{t}=2.157, \mathrm{p}=.032,360 \mathrm{df}$, equal variances assumed, Levene's test for equality of variances: $\mathrm{F} 1=.051, \mathrm{p}=.306$, Cohen's $\mathrm{d}=.23$ ). Since overall the gender differences were immaterial, and the effect sizes were relatively small, the following analyses did not look further for gender effects.

\begin{tabular}{|c|c|c|c|c|}
\hline \multicolumn{5}{|c|}{$\begin{array}{l}\text { Table 1: Perceptions iOS and Android operating system users of } \\
\text { advantages and disadvantages of smartphones }\end{array}$} \\
\hline Characteristics & $\begin{array}{l}\text { iOS } \\
(n=247) \\
\text { mean (SD) }\end{array}$ & $\begin{array}{l}\text { Android } \\
(\mathrm{n}=115) \\
\text { mean (SD) }\end{array}$ & $\begin{array}{l}\text { t-test } \\
\text { (sig.,2-tailed) } \\
n=362, d f=360 *\end{array}$ & $\begin{array}{l}\text { Levene's test for } \\
\text { equality of variances } \\
\text { F (sig.) }\end{array}$ \\
\hline Advantage: anytime & $3.43(.890)$ & $3.41(.782)$ & $.253(.800)$ & $.905(.342)$ \\
\hline Advantage: anywhere & $3.55(.763)$ & $3.49(.788)$ & $.685(.494)$ & $.473(.492)$ \\
\hline Advantage: image & $1.89(1.019)$ & $2.03(1.042)$ & $-1.209(.228)$ & $.060(.807)$ \\
\hline Advantage: accessible & $3.42(.781)$ & $3.33(.780)$ & $1.028(.305)$ & $.002(.967)$ \\
\hline Advantage: comfortable & $2.64(1.076)$ & $2.40(1.066)$ & $2.013(.045)$ & $.065(.799)$ \\
\hline $\begin{array}{l}\text { Advantage: sharing } \\
\text { information }\end{array}$ & $2.65(1.036)$ & $2.51(1.150)$ & $\begin{array}{l}1.103(.272) \\
\mathrm{df}=203.024 *\end{array}$ & $4.804(.029)^{*}$ \\
\hline Disadvantage: security & $2.81(1.013)$ & $2.73(1.037)$ & $.653(.514)$ & $.272(.602)$ \\
\hline Disadvantage: price & $2.81(1.000)$ & $2.72(1.022)$ & $.774(.440)$ & $.226(.635)$ \\
\hline Disadvantage: complex & $3.23(.892)$ & $2.89(1.033)$ & $3.244(.001)$ & $2.639(.105)$ \\
\hline Disadvantage: small & $2.70(.974)$ & $2.63(.995)$ & $.708(.480)$ & $.111(.739)$ \\
\hline
\end{tabular}

* Since Levene's test was significant, the values were selected accordingly. 
Table 1 compares the perceptions of 247 participants who use iOS for Apple operating systems, with those of the 115 Android users. As can be seen in Table 1, there were significant differences in the perceptions of two characteristics: comfortableness and complexity. The effect size was small for comfortableness (Cohen's d=0.22), and medium for complexity (Cohen's d=0.35).

The next phase of the analysis examined the impact of length of possession of the smartphone, measured by reported months (mean=13.89 months, $\mathrm{SD}=8.876$ ), on the perceptions of its characteristics. Pearson correlation tests resulted in no significant correlations, except for image (Pearson correlation $=.112, \mathrm{p}=.017, \mathrm{n}=362$, one-tailed), which was relatively small. The tests were repeated separately for $\mathrm{iOS}$, with similar results (i.e., just the image characteristic was significant, Pearson correlation $=.112, \mathrm{n}=247, \mathrm{p}=.011$, one-tailed) and for Android, where no significant correlation was found. Table 2 presents the characteristics, ordered by their values. The main perceived advantages of smartphone compared with stationary internet services are: the abilities to use it anywhere, anytime, and its being accessible. Its severest drawback is its small size, whereas complexity is considered as a light disadvantage.

\begin{tabular}{|l|l|}
\hline \multicolumn{2}{|c|}{ Table 2: Relative perceptions of } \\
\hline Chantages and disadvantages of smartphones \\
\hline $\begin{array}{l}\text { Advantages (ordered from the biggest ranked advantage relative to } \\
\text { the use of stationary computer) }\end{array}$ \\
\hline mean (SD) \\
\hline Advantage: anywhere & $3.53(.770)$ \\
\hline Advantage: anytime & $3.43(.856)$ \\
\hline Advantage: accessible & $3.39(.781)$ \\
\hline Advantage: sharing information & $2.61(1.074)$ \\
\hline Advantage: comfortable & $2.57(1.077)$ \\
\hline Advantage: image & $1.94(1.027)$ \\
\hline Disadvantages (ordered from the most severest disadvantage relative \\
to the use of a stationary computer)
\end{tabular}




\section{Discussion}

\section{Theoretical Implications}

This study presented three specific research questions, generating from a global question of whether operating systems affect smartphone possessors' perceptions of advantages and drawbacks of their device usage, when compared with consuming the same services via a computer.

RQ1 differentiated between general and operating-system-related characteristics. H1, which suggested that there are no differences between users of alternative operating systems in their perceptions of general advantages and drawbacks of smartphone use for consumption of internet services, was supported. All the eight examined general characteristics (i.e., anytime, anywhere, accessibility, sharing, image, security, small, and price), were perceived similarly by users of iOS and Android. H2, which suggested that there will be differences in the perceptions of operatingsystem-related characteristics (i.e., comfortableness and complexity), was supported, as well. The iOS was perceived better than Android in both aspects. However, the effect sizes were low to medium. These results coincide with the currently prevailing public perception that iOS is more user friendly than Android. Nevertheless, the small differences suggest that people tend to perceive what they have as more valuable (Wolf, Arkes, \& Muhanna, 2008). This psychological phenomenon is known as the "endowment effect", and has been widely studied (Kahneman, Knetsch, \& Thaler, 1990).

RQ2 dealt with gender differences, and the two related hypotheses that suggested that no gender differences were expected were by-and-large supported. There were a few small differences (image, security, and complexity), but the effect sizes were small to low medium level. These findings may seem somewhat surprising because women are often perceived as less inclined to adopt new technologies, and as having a harder time learning how to use such technologies. Plausible explanations may be that the perceptions are wrong, or that the perceptions do not apply to generation $\mathrm{Y}$, or that since a smartphone is a personal device that offers rewarding applications, women invest the necessary effort, and quickly learn how to use it. Future research may examine this issue during the first week after acquiring the smartphone.

RQ3 examined the effect of period of possession on user perceptions. H5 was supported, and no correlation was found between period of possession, expressed in months, and general smartphone characteristics. But H6 was not supported, and no significant correlation was found between period of possession and the smartphone operating-system-related advantages and drawbacks. Again, as with the gender differences discussed above, perhaps people adjust within days of the smartphone purchase.

\section{Practical Implications}

The findings of this study propose that either people select the operating system that suits their preferences, or that people adjust, or they rationalize their buying decisions (Wolfet al., 2008). Currently, iOS and Android are considered as two distinct operating systems. However, as time goes by, these two operating systems, as well as others, will become similar, as the new versions of each of the operating systems adopt the advantages introduced by prior competing systems.

\section{Limitations and Directions for Further Research}

The use of smartphones is fast spreading. However, so far, just a few studies examined their adoption. Furthermore, at the time of data collection, May 2012, the proportion of smartphone users within the general population was small. Therefore, this study used snowball sampling (Corbitt et al., 2003; Peffers \& Tuunanen, 2005). In order to corroborate the findings of this study, it should be repeated with larger random samples. 
Moreover, the study was purposely based on homogenous participants, who mostly lived in the same region in central Israel, and belonged to the same middle class socio-economic group. They were 20-30 years old, and were under similar cultural influences. It appears that the most relevant demographic is the age group. The results may not be applicable to other age groups. Additionally, the results may be relevant only to generation Y, i.e., people that were born between the years 1982-2000, or even just the older half of that generation. Hence, further study needs to examine other age groups. Cultural differences should also be further investigated.

\section{Conclusion}

The findings of this study suggest that ex-post, after a person has already acquired a smartphone, it does not really matter which operating system the device uses. No material differences were found in the perceptions of iOS and Android users regarding the advantages and disadvantages of smartphone use compared to consuming the same services via a computer. Likewise, no substantial gender differences and no effect of the period of possession were indicated. However, this empirical study examined the perceptions of generation $\mathrm{Y}$ users. It may not be applicable to other generations, especially older ones. Further study is required to determine whether generation $Y$ users simply know how to select a smartphone that suits them based on the vast information available on the various operating systems, or they adjust to whatever device they have chosen within days or a few weeks. It may well be a combination of the two explanations.

\section{References}

Barnes, S. J., \& Huff, S. L. (2003). Rising sun: iMode and the wireless internet. Communications of the $A C M, 46(11), 78-84$.

Cheong, C., Bruno, V., \& Cheong, F. (2012). Designing a mobile-app-based collaborative learning system. Journal of Information Technology Education: Innovations in Practice, 11, 97-119. Retrieved from http://www.jite.org/documents/Vol11/JITEv11IIPp097-119Cheong1092.pdf

Cohen, E. (1999). Reconceptualizing information systems as a field of the transdiscipline informing science: From ugly duckling to swan. Journal of Computing and Information Technology, 7(3), 213-219.

Cohen, E. (2009). A philosophy of informing science. Informing Science: the International Journal of an Emerging Transdiscipline, 12, 1-15. Retrieved from http://inform.nu/Articles/Vol12/ISJv12p001015Cohen399.pdf

Corbitt, B. J., Thanasankit, T., \& Yi, H. (2003). Trust and e-commerce: A study of consumer perceptions. Electronic Commerce Research and Applications, 2(3), 203-215. doi:10.1016/S1567-4223(03)000243

Gafni, R. (2008). Framework for quality metrics in mobile-wireless information systems. Interdisciplinary Journal of Information, Knowledge, and Management, 3, 23-38. Retrieved from http://ijikm.org/Volume3/IJIKMv3p023-038Gafni358.pdf

Gafni, R. (2009). Usability issues in mobile-wireless information systems. Issues in Informing Science and Information Technology, 6, 755-769. Retrieved from http://iisit.org/Vol6/IISITv6p755769Gafni608.pdf

Gafni, R., \& Geri, N. (2013). Generation Y versus generation X: Differences in smartphone adaptation. In Y. Eshet-Alkalai, A. Caspi, S. Eden, N. Geri, Y. Kalman, \& Y. Yair (Eds.), Learning in the technological era: Proceedings of the Chais conference on instructional technologies research (pp. 18-23). February 19-20, 2013, Raanana, The Open University of Israel.

Garland, R. (1991). The mid-point on a rating scale: Is it desirable? Marketing Bulletin, 2, 66-70. Retrieved from http://marketing-bulletin.massey.ac.nz/V2/MB V2_N3 Garland.pdf 
Gerpott, T. J., Thomas, S., \& Weichert, M. (2012). Characteristics and mobile Internet use intensity of consumers with different types of advanced handsets: An exploratory empirical study of iPhone, Android and other web-enabled mobile users in Germany. Telecommunications Policy, forthcoming.

Gill, T. G., \& Bhattacherjee, A. (2009). Whom are we informing? Issues and recommendations for MIS research from an informing science perspective. MIS Quarterly, 33(2), 217-235.

Gill, T. G., \& Cohen, E. (Eds.). (2009). Foundations of informing science, 1999-2008. Santa Rosa, CA: Informing Sciences Press.

Ho, S. C., \& Tu, Y. C. (2012). The investigation of online reviews of mobile games. E-Life: Web-Enabled Convergence of Commerce, Work, and Social Life, 108, 130-139. doi:10.1007/978-3-642-29873-8_13

Jeyaraj, A., Rottman, J. W., \& Lacity, M. C. (2006). A review of the predictors, linkages, and biases in IT innovation adoption research. Journal of Information Technology, 21(1), 1-23.

Jiang, P. (2009). Consumer adoption of mobile internet services: An exploratory study. Journal of Promotion Management, 15, 418-454.

Jones, M. (2012). The evolution of digital technologies - from collaboration to eCollaboration - and the tools which assist eCollaboration. Issues in Informing Science and Information Technology, 9, 209219. Retrieved from http://iisit.org/Vol9/IISITv9p209-219Jones122.pdf

Kahneman, D., Knetsch, J. L., \& Thaler, R. H. (1990). Experimental tests of the endowment effect and the Coase theorem. Journal of Political Economy, 98, 1325-1348.

Kumar, A., \& Lim, H. (2008). Age differences in mobile service perceptions: comparison of Generation Y and baby boomers. Journal of Services Marketing, 27(7), 568-577.

Laugesen, J. \& Yuan, Y. (2010). What factors contributed to the success of Apple's iPhone. 2010Ninth International Conference on Mobile Business / 2010 Ninth Global Mobility Roundtable, 91-99. doi: 10.1109/ICMB-GMR.2010.63

Limayem, M., Hirt, S. G., \& Cheung, C. M. K. (2007). How habit limits the predictive power of intention: The case of information systems continuance. MIS Quarterly, 31(4), 705- 737.

Morris, M. G., \& Venkatesh, V. (2000). Age differences in technology adoption decisions: Implications for a changing work force. Personnel Psychology, 53, 375-403.

Peffers, K., \& Tuunanen, T. (2005). Planning for IS applications: A practical, information theoretical method and case study in mobile financial services. Information \& Management, 42(3), 483-501. doi:10.1016/j.im.2004.02.004

Polites, G. L., \& Karahanna, E. (2012). Shackled to the status quo: The inhibiting effects of incumbent system habit, switching costs, and inertia on new system acceptance. MIS Quarterly, 36(1), 21-42.

Rogers, E. M. (2003). Diffusion of innovation, 5th edition, New-York: The Free Press.

Smith A. (2011). 35\% of American adults own a smartphone. Pew Research Center. Retrieved from http://pewinternet.org/Reports/2011/Smartphones.aspx

Subramanian, R., \& White, B. (2012). Teaching IS to the information society using an "informing science" perspective. Informing Science: the International Journal of an Emerging Transdiscipline, 15, 147182. Retrieved from http://www.inform.nu/Articles/Vol15/ISJv15p147-182Subramanian0601.pdf

Venkatesh, V., Morris, G. M., Davis, G. B., \& Davis, F. D. (2003). User acceptance of information technology: Toward a unified view. MIS Quarterly, 27(3), 425-478.

Venkatesh, V., Thong, Y. L. J., \& Xu, X. (2012). Consumer acceptance and use of information technology: Extending the unified theory of acceptance and use of technology. MIS Quarterly, 36(1), 157-178.

Verkasalo, H., López-Nicolás, C., Molina-Castillo, F. J., \& Bouwman, H. (2010). Analysis of users and non-users of smartphone applications. Telematics and Informatics, 27(3), 242-255. doi:10.1016/j.tele.2009.11.001 
Wolf, J. R., Arkes, H. R., \& Muhanna, W. A. (2008). The power of touch: An examination of the effect of duration of physical contact on the valuation of objects. Judgment and Decision Making 3(6), 476482 .

Wong, L.-H., Boticki, I., Sun, J., \& Looi, C.-K. (2011). Improving the scaffolds of a mobile-assisted Chinese character forming game via a design-based research cycle. Computers in Human Behavior, 27(5), 1783-1793. doi:10.1016/j.chb.2011.03.005

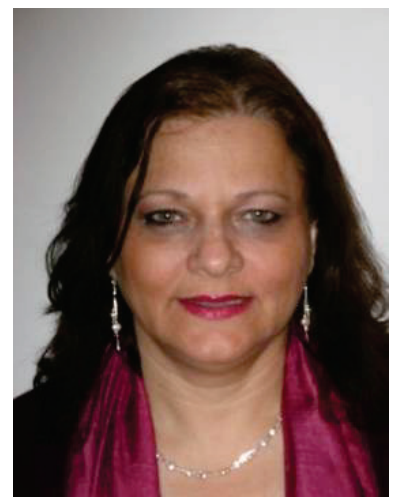

\section{Biographies}

Ruti Gafni is a faculty member in the Management of Information Systems BA program at Tel Aviv-Yaffo Academic College. She holds a PhD from Bar-Ilan University, Israel, in the Business Administration School, focusing on Information Systems. She holds an M.Sc. in Management Sciences from Tel Aviv University and a BA (Cum Laude) in Economics and Computer Science from Bar-Ilan. She has more than 30 years of practical experience as project manager and analyst of information systems. She also teaches in the MBA program of the Management and Economics department at the Open University of Israel.

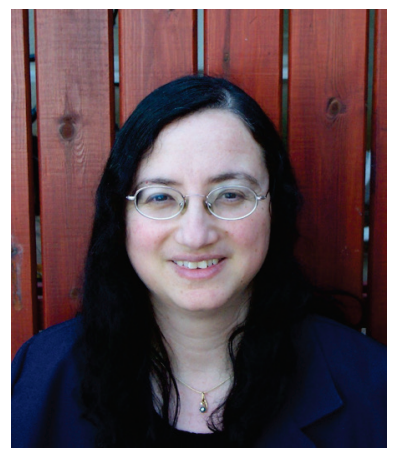

Nitza Geri is a faculty member at the Open University of Israel, Department of Management and Economics, and Head of the Research Center for Innovation in Learning Technologies. She holds a B.A. in Accounting and Economics, an M.Sc. in Management Sciences and a $\mathrm{Ph} . \mathrm{D}$. in Technology and Information Systems Management from TelAviv University. Nitza is a CPA (Israel) and prior to her academic career she had over 12 years of business experience. Her research interests and publications focus on various aspects of the value of information, and information systems adoption and implementation, including strategic information systems, e-business, economics of information goods, attention economy, value creation and the Theory of Constraints, managerial aspects of e-learning systems adoption and use. Personal site: http://www.openu.ac.il/Personal_sites/nitza-geri.html 